\title{
Electroplating Technique for Sealing of Thermal Sprayed Coating to Enhance Corrosion Resistance*
}

\author{
Hathaipat KOIPRASERT** and Panadda NIRANATLUMPONG** \\ ** National Metal and Materials Technology Center (MTEC) \\ 114 Thailand Science Park, Paholyothin Rd., \\ Klong 1, Klong Luang, Pathumthani 12120, Thailand. \\ E-mail: hathaik@mtec.or.th
}

\begin{abstract}
This research compared the corrosion behavior of the Ni plated and the un-plated Hastelloy C-276 and stainless steel 316 EAS coatings in $2 \mathrm{M} \mathrm{NaOH}$ solution at $25^{\circ} \mathrm{C}$ using electrochemical technique. The results can be summarized that $\mathrm{Ni}$ plating of approximately 10 microns thick as a sealant can improve the corrosion resistance of the EAS coatings. The as sprayed Hastelloy C-276 coating exhibits higher corrosion rate than the as sprayed stainless steel 316 coating. The corrosion behavior can be improved further by smoothening of the EAS coating surface before plating. The corrosion resistance of the smoothened Hastelloy C-276 coatings, both plated and un-plated, are superior to those of the stainless steel 316 coatings.
\end{abstract}

Key words: Thermal Sprayed Coating, Electroplating, Coating Sealants, Corrosion, Electrochemical Test

\section{Introduction}

Electric arc spraying (EAS) is one of the thermal spraying techniques, used for protection of parts and components from corrosion and corrosive wear in many industries because this technique can build up several millimeters of coatings rapidly and economically. Therefore, EAS is widely used in restoration of equipments. The principle of EAS involves two current carrying, electrically conductive wires fed into a common arc point creating a temperature of up to the melting point of the wire material at which melting occurs. The temperature at the wire tips can be as high as $1,500^{\circ} \mathrm{C}^{(1)}$. The molten material is continuously atomized and the droplets are accelerated toward the substrate by a compressed air jet. One problem in using the EAS coating is its high porosity, which can be as high as $3-8 \%{ }^{(2)}$ making it not appropriate for uses in immersion conditions and in high humidity conditions, in which corrosive media can penetrate through the coating porosities to the substrates. This can accelerate the corrosion and the corrosive wear, leading to pre-mature failure of the coatings.

Electroplating of nickel is widely used for protection from corrosion in many industries. Thailand has a large number of Ni plating facilities, due to its low price. But the electroplating of nickel has a limited thickness of no more than about $0.1 \mathrm{~mm}{ }^{(3)}$, which is not sufficient for part restoration where a large bulk of material is damaged.

This project is therefore carried out based on the idea of using Ni plating to seal the surface porosity of the EAS coatings to enhance the corrosion resistance. The resulted sealed coatings are expected to achieve higher corrosion resistance and to be more durable 
than the conventional polymer sealants.

2. Experimental Procedure

Table1. Spray parameters for Electric arc spraying technique.

\begin{tabular}{|l|c|c|}
\hline & Hastelloy C-276 coating & Stainless steel 316 coating \\
\hline Air pressure (bar) & 4.27 & 4.14 \\
\hline Arc load (Volt) & $30-34$ & 30 \\
\hline Arc current (Amp.) & $150-160$ & $165-170$ \\
\hline Spray distance (mm.) & 152 & 178 \\
\hline
\end{tabular}

Table 2 Sample preparation details.

\begin{tabular}{|c|c|c|c|c|c|}
\hline $\begin{array}{l}\text { Sample } \\
\text { group }\end{array}$ & \begin{tabular}{|c|} 
Substrate \\
Stainless steel 304
\end{tabular} & $\begin{array}{c}\text { Hastelloy } \\
\text { C- } 276 \text { coating }\end{array}$ & $\begin{array}{c}\text { Stainless steel } \\
316 \text { Coating }\end{array}$ & Surface grinding & Ni plating \\
\hline 1 (ref.) & $\mathrm{x}$ & & & $\mathrm{x}$ & \\
\hline 2 & $\mathrm{x}$ & $\mathrm{x}$ & & & \\
\hline 3 & $\mathrm{x}$ & $\mathrm{x}$ & & $\mathrm{x}$ & \\
\hline 4 & $\mathrm{x}$ & $\mathrm{x}$ & & & $\mathrm{x}$ \\
\hline 5 & $\mathrm{x}$ & $\mathrm{x}$ & & $\mathrm{x}$ & $\mathrm{x}$ \\
\hline 6 & $\mathrm{x}$ & & $\mathrm{x}$ & & \\
\hline 7 & $\mathrm{x}$ & & $\mathrm{x}$ & $\mathrm{x}$ & \\
\hline 8 & $\mathrm{x}$ & & $\mathrm{x}$ & & $\mathrm{x}$ \\
\hline 9 & $\mathrm{x}$ & & $\mathrm{x}$ & $\mathrm{x}$ & $\mathrm{x}$ \\
\hline
\end{tabular}

The substrates for 9 group of sample were made by cutting a flat stainless steel 304 bar into specimen of dimension 20x20x3 mm. For the sample group 1, which was a reference sample, the substrates were surface ground to achieve a surface roughness of less than 0.1 $\mu \mathrm{m} \mathrm{Ra}$ and leave to stand for 24 hours to allow for the build-up of passive films before the electrochemical test. The sample groups 2-9, which were to be coated, roughened by grit blasting using a 740 micron alumina grit to obtain a sharp peaked surface contour, with the substrate surface roughness of approximately $4.6 \mu \mathrm{m} \mathrm{Ra}$, to promote a good coating adhesion. The air pressure used for grit blasting was 7 bars. The blasting nozzle was held perpendicular to the sample surface at a distance of $80 \mathrm{~mm}$. for 30 seconds. After the grit blasting process, the samples were cleaned in acetone using an ultrasonic bath for 15 minutes. The samples were then ready for electric arc spraying using TAFA 9000 system to produce coatings of approximately $500 \mu \mathrm{m}$ thick. The sample groups $2-5$ were then coated using Hastelloy C-276 wire (nominal composition of 55Ni-15.5Cr-16Mo-4W-5.5Fe, in wt. $\%$ ) and the sample groups 6-9 were coated using TAFA 85T stainless steel 316 wire (nominal composition of $12 \mathrm{Ni}-17 \mathrm{Cr}-2.5 \mathrm{Mo}-0.08 \mathrm{C}-2 \mathrm{Mn}-1 \mathrm{Si}-\mathrm{Fe}($ bal.), in wt.\%) as the coating materials. The spray parameters used in this experiment were optimized for the coating to obtain a uniform, high-density, good adhesion coatings with a low oxide content. These parameters are shown in Table 1. The sample groups 3, 5, 7 and 9 were ground using wet $\mathrm{SiC}$ papers after the coating process to achieve a coating surface roughness of $0.2 \mu \mathrm{m}$ $\mathrm{Ra}$, and still leaving a coating thickness of $400 \mu \mathrm{m}$ on the substrate. The specified sample groups were then electroplated with nickel using an in-house electroplating equipment. The samples were electroplated using Watt's solution ${ }^{(4)}$, with the power supply voltage $2.5 \mathrm{~V}$ and the current of $0.1 \mathrm{~A}$, with the plating time of $10 \mathrm{~min}$. for Nickel layer of $10 \mu \mathrm{m}$ thick. A summarize of each sample preparation was shown in Table2. The as-plated samples were cross-sectioned to study the sealing ability of the Nickel plating using a scanning electron microscope. Sample 10, the Hactelloy C-276 wire and sample 11, the stainless steel 316 wire, were also tested for comparison.

The corrosion resistance of the samples was investigated in an electrochemical polarization experiment using potentiodynamic method. The test utilized a preset program called "General propose electrochemistry system" (GPES) by Autolab potentiostat 
equipment. The electrolyte was $2 \mathrm{M} \mathrm{NaOH}$ solution ( $\mathrm{pH} 12.5)$, the test sample was set up as the working electrode and $\mathrm{Ag} / \mathrm{AgCl}$ was used as the reference electrode. The platinum mesh auxiliary electrode supplied the current to the working electrode in order to polarize it. The potential between the working and the reference electrodes was measured and controlled to increase in fixed intervals while the current flow was measured. The testing temperature was $25^{\circ} \mathrm{C}$. Testing was done at a scan rate of $0.01 \mathrm{~V} / \mathrm{sec}$. The test result is presented in the form of the polarization curve, which is the plot of the electrode potential (E) versus the log of the current density (I). At least 3 specimens per each group of samples were tested using the potentiodynamic technique and Tafel extrapolation method in order to calculate the average corrosion potentials $\left(\mathrm{E}_{\text {corr }}\right)$ and corrosion rates of the test samples. The results for sample groups $1-5$ have been previously reported. ${ }^{(5)}$

\section{Results \& Discussion}

\subsection{Corrosion behavior of the substrate and the coating materials}

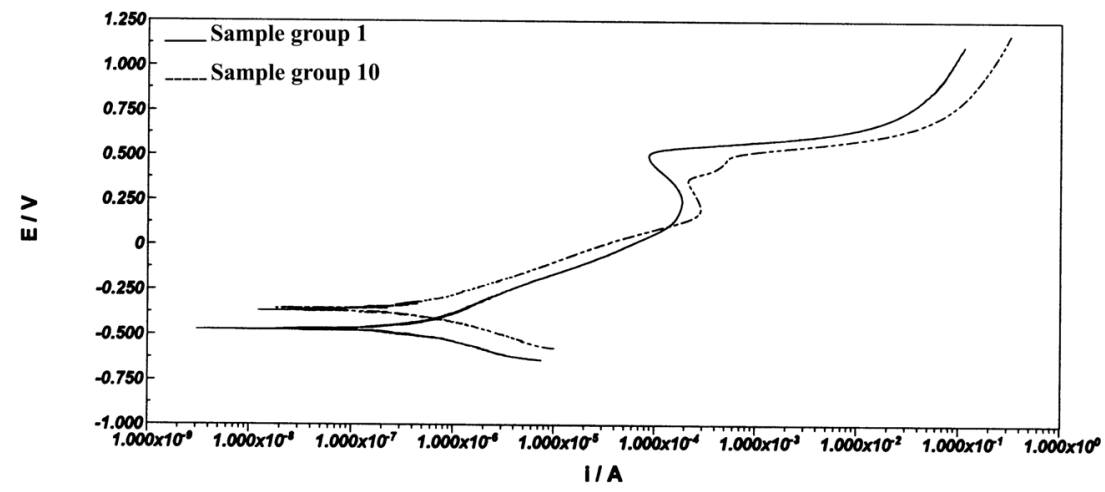

Fig. 1 Polarization curves between the bulk stainless steel substrate (sample group 1) and Hastelloy C-276 wire (sample group 10) tested in $2 \mathrm{M} \mathrm{NaOH}$.

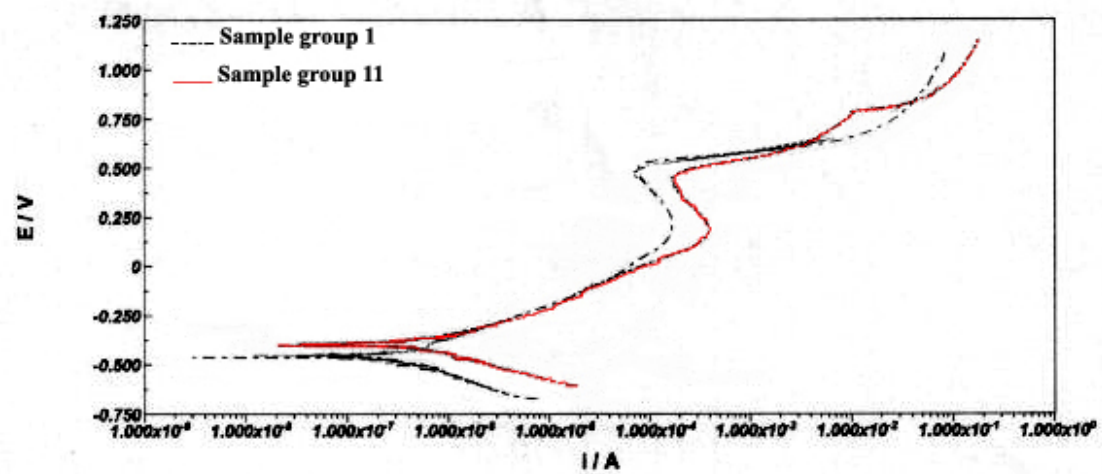

Fig. 2 Polarization curves of the bulk stainless steel 304 substrate (sample group 1) and the stainless steel 316 wire (sample group 11) tested in $2 \mathrm{M} \mathrm{NaOH}$.

The polarization curves of a bulk stainless steel 304 sample in comparison with the Hastelloy C-276 wire and the stainless steel 316 wire, which both of wires were used for EAS coating, are shown in Fig. 1 and Fig. 2 respectively. The $\mathrm{E}_{\text {corr }}$ value of the bulk stainless steel 304 sample is lower than that of the Hastelloy C-276 and the stainless steel 316 wires, which indicate that the stainless steel 304 sample corrodes easier than the Hastelloy C-276 and stainless steel 316 wires. The passive film of the bulk stainless steel 304 sample and the stainless steel 316 wire show similar behavior while, the Hastelloy C-276 wire formed a secondary oxide film. During the test, $\mathrm{Fe}(\mathrm{OH})_{2}, \mathrm{Ni}(\mathrm{OH})_{2}, \mathrm{Cr}(\mathrm{OH})_{3}$ and possibly other oxides and spinels can form on the surface as a passive layer. Figure 1 shows that the stainless steel 304 sample form an oxide film, possible of $\mathrm{Cr}$, at the potential 
range from $0.2 \mathrm{~V}$ to $0.5 \mathrm{~V}$, which coincides with a result from previous research ${ }^{(6)}$, after which the film starts to break down. The Hastelloy C-276 wire exhibits two regions relating to the formation of oxide films, which overlap. These the oxides are $\mathrm{Ni}$ and $\mathrm{Cr}$ oxide films. At pre-passive region, $\mathrm{Ni}$ dissolves to $\mathrm{Ni}^{2+}$ and forms $\mathrm{Ni}(\mathrm{OH})_{2}{ }^{(7)}$ at the potential ranges of $0.12 \mathrm{~V}$ to $0.35 \mathrm{~V}$. After that, at the potential between $0.35 \mathrm{~V}$ to $0.4 \mathrm{~V}$, the behavior becomes transpassive, the corrosion occurs preferentially at grain boundaries and $\mathrm{Ni}^{2+}$ ions dissolve into the solution. At higher potentials nickel exhibits secondary passive film. At the potential of $0.5 \mathrm{~V}$ which is above the range of the secondary passivity the anodic current density increases and dissolution proceeds through the oxide film, $\mathrm{Ni}(\mathrm{OH})_{2}$ to $\mathrm{NiOOH}$ transition occurred. ${ }^{(6)(7)}$ Fig. 2 shows the similar corrosion behavior of the bulk stainless steel 304 sample and the stainless steel 316 wire, which form the protective oxide film of chromium at the same potential range. However, from Fig. 1, it was found that the Hastelloy C-276 has slightly lower corrosion rate than the bulk stainless steel 304 while Fig. 2 show the stainless steel 316 wire has slightly higher corrosion rate than the bulk stainless steel 304.

\subsection{Effect of coating and surface roughness on the corrosion behavior}

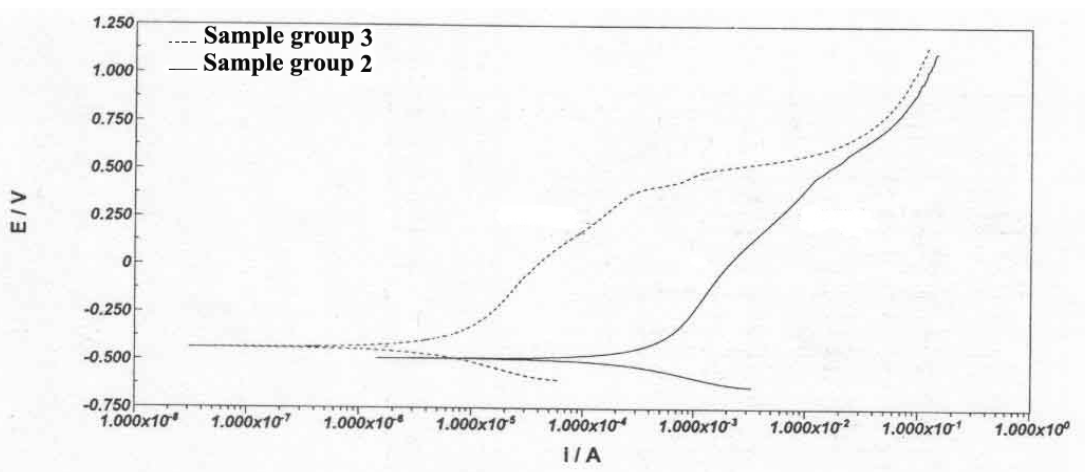

Fig. 3 Polarization curves of the as sprayed Hastelloy C-276 coating (sample group 2) and the ground Hastelloy C-276 coating (sample group 3).

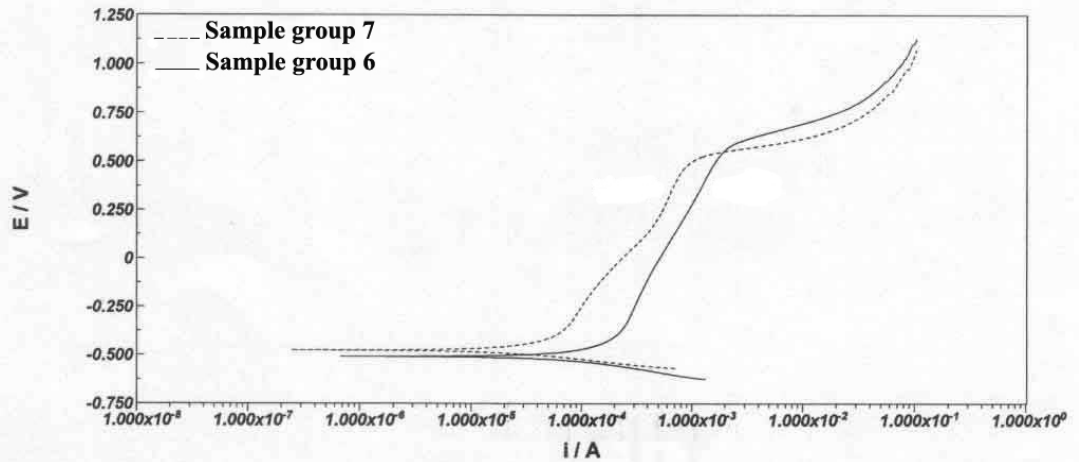

Fig. 4 Polarization curves of the as sprayed stainless steel 316 coating (sample group 6) and the ground stainless steel 316 coating (sample group 7).

After spraying, the polarization curves of sample group 2 (as sprayed Hastelloy C-276 coating) and sample group 3 (ground Hastelloy C-276 coating) are shown in Fig. 3 and the polarization curves of sample group 6 (as sprayed stainless steel 316 coating) and sample group 7 (ground stainless steel 316 coating) are shown in Fig. 4. The polarization curve of each coating is difference from its original material which show in Fig. 1 and Fig. 2. The formation of passive films is now not evidenced. This is thought to be because the arc sprayed coating is formed by individual splat depositions, the intersplat pores are common. These pores cause the discontinuity in the formation of the protective oxide film, which 
leads to the decreasing in the ability to hinder the oxidation of the surface coating. Moreover, thermal effect from the arc temperature of around $1,500^{\circ} \mathrm{C}$ resulted in the reduction of chromium and nickel content, as shown in the EDS analysis in Table 3

Table 3 Average chemical compositions of the Hastelloy C-276 wire, the stainless steel 316 wire and the coating produced from the same wire using the quantitative EDS analysis.

\begin{tabular}{|l|c|c|c|c|c|c|c|c|}
\hline & \multicolumn{7}{|c|}{ Chemical composition (Average wt.\%) } \\
\cline { 2 - 10 } & $\mathrm{Fe}$ & $\mathrm{Cr}$ & $\mathrm{Ni}$ & $\mathrm{Mo}$ & $\mathrm{C}$ & $\mathrm{W}$ & $\mathrm{Si}$ & $\mathrm{O}$ \\
\hline Hastelloy C276 wire & 5.64 & 14.95 & 56.32 & 14.77 & 4.43 & 3.88 & - & - \\
\hline Hastelloy C276 coating & 5.22 & 13.75 & 54.43 & 15.90 & 1.70 & 3.99 & - & 5.03 \\
\hline Stainless steel 316 wire & 59.63 & 18.41 & 10.29 & 4.71 & 4.84 & - & 1.45 & - \\
\hline Stainless steel 316 coating & 59.99 & 12.67 & 10.23 & 5.69 & 2.93 & - & 0.52 & 8.28 \\
\hline
\end{tabular}

In Fig.3 and Fig.4, The ground coating exhibits lower current density than the as sprayed coating, which indicates that the corrosion rate of the ground coating is lower than the as sprayed coating. This is because, in the arc spraying process, the coating achieves its density by deformation of the material droplets to the contour of the underlying surface upon impact. The density can then be increased further by the compressive force induced by the next impacting droplets, which assists in the splat compaction. The surface layer of the coating, however, was not further bombarded by the molten droplets, and therefore, tends to have larger intersplat pores. When the coating surface was ground down to achieve the surface roughness of approximately $0.2 \mu \mathrm{m} \mathrm{Ra}$, the surface layer was removed. At the same time, the depth of the pit was also reduced with the new surface being denser with pores smaller in size, and hence, the lower current density can be achieved. Cross-sections of the as sprayed stainless steel 316 and the ground stainless steel 316 coatings are shown in Fig.5 (a) and (b). The shallower surface pit allows better circulation of the solution, which promotes the formation of the protective scale. The scale formation and breakdown cycle are not clearly visible in Fig. 3 and Fig. 4, but a decrease in the corrosion rate as the test progressed suggests the presence of the protective film.

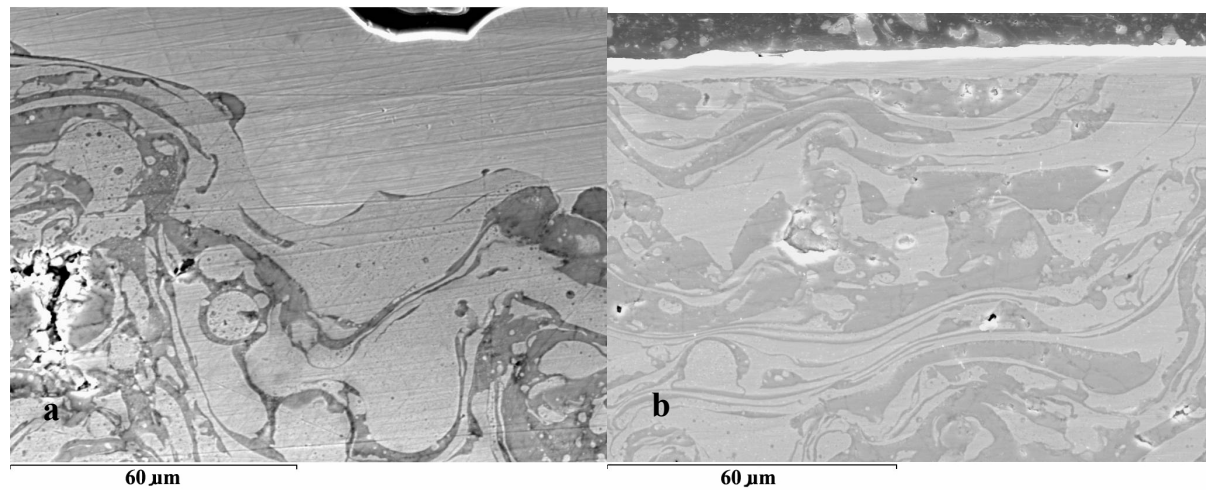

Fig. 5 (a) Cross-section of the as sprayed stainless steel 316 coating.

(b) Cross-section of the ground stainless steel 316 coating.

\subsection{Effect of Ni electroplating on the corrosion behavior}

Corrosion and corrosive wear protection process of a Ni plated coating is shown in Fig. 6. Commonly the applications of the EAS coating were not permitted in immersion and high humidity condition, with an exception of a sacrificial anode, because the corrosive solution can penetrate through the intersplat pores in the coating to the substrate. After using the electroplating of $\mathrm{Ni}$ to seal the coating porosity, the corrosive solution can be retarded from penetrating through the pores. In corrosive wear condition, after the Ni plating is removed through wear process, some Ni plating is still remained in the pore, preventing the 
solution from penetrating into the coating and the substrate, which help to improve the corrosion resistance of the thermal sprayed coating.
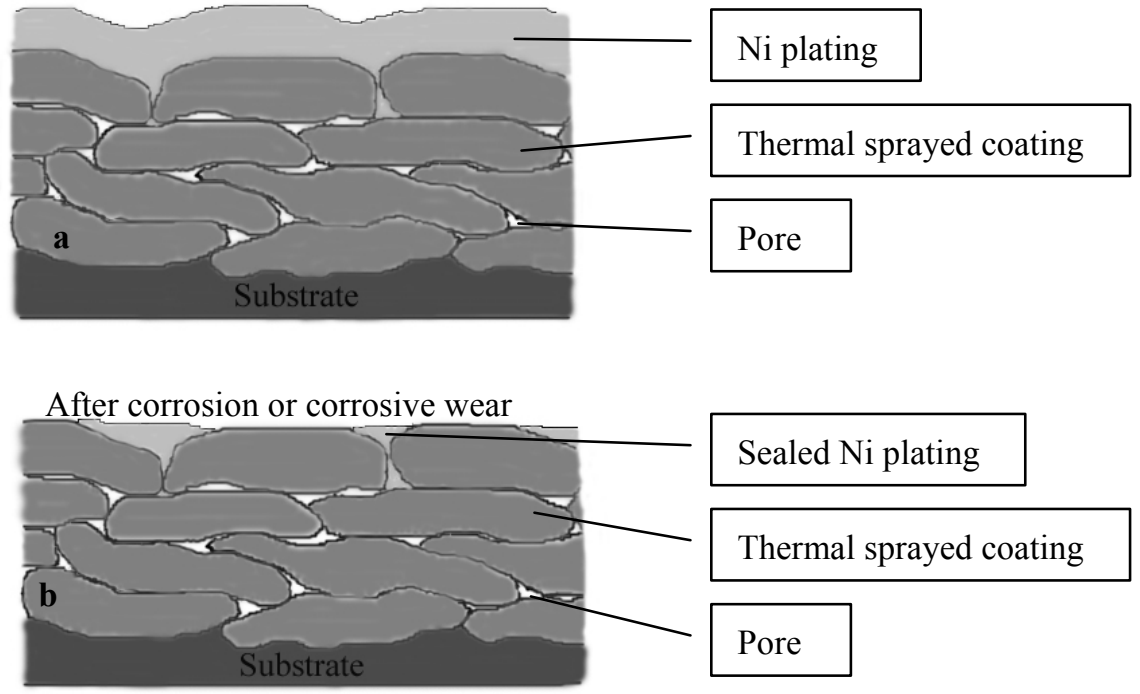

Fig. 6 Thermal sprayed coating sealed by Ni plating.

The polarization curve of the Ni plated and the un-plated, non-smoothened Hastelloy $\mathrm{C}-276$ coatings are shown in Fig. 7. The $\mathrm{E}_{\text {corr }}$ value of the Ni plated sample is lower than that of the un-plated, which indicates that the Ni plated layer corrodes easier than the un-plated Hastelloy C-276 coating. The Ni plated samples exhibits a formation of the secondary passive film, with the possible passive layer of $\mathrm{Ni}(\mathrm{OH})_{2}{ }^{(6)(7)}$. The corrosion is now taking place on the nickel layer instead of the Hastelloy C-276 coating. Moreover, the Ni plated sample possessed higher durability than the un-plated coating, as can be observed in the slightly lower current density that means the corrosion rate of the Ni plated sample is also lower than the un-plated. The test results on the sample group 6 (as sprayed stainless steel 316 coating) and group 8 (Ni plated stainless steel 316 coating) to have similar potentials show in Fig.8. For sample group 8, corrosion is also taking place on the nickel layer instead of the stainless steel 316 coating. The Ni plating exhibits a formation of the secondary passive film which the same corrosion behavior as the sample group 4 (the $\mathrm{Ni}$ plated Hastelloy C-276 coating).

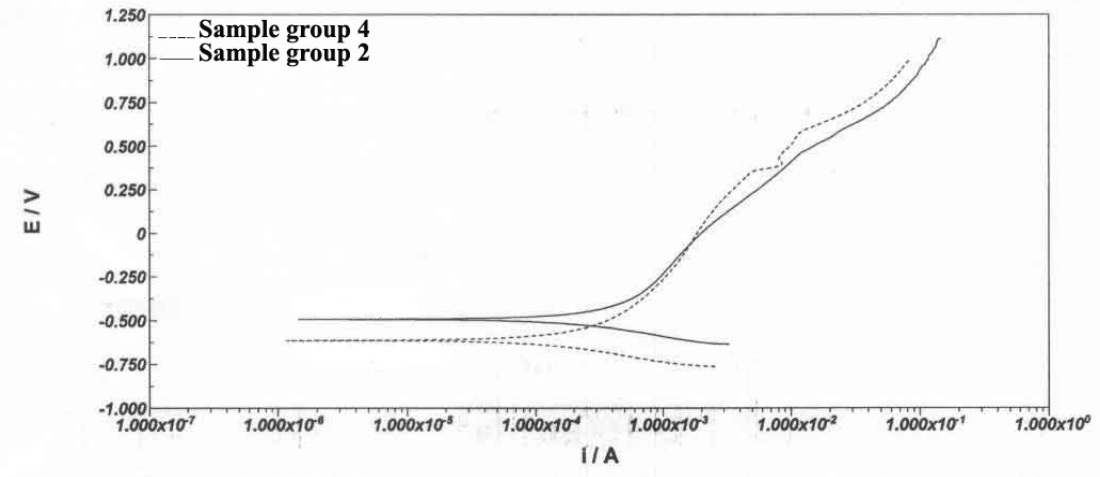

Fig. 7 Polarization curves of the as sprayed Hastelloy C-276 coating (sample group 2) and the Ni plated Hastelloy C-276 coating (sample group 4). 


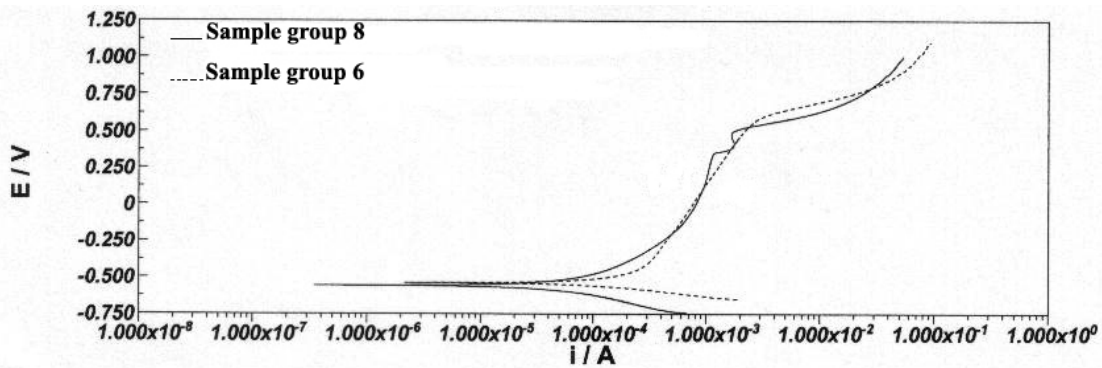

Fig. 8 Polarization curves of the as sprayed stainless steel 316 coating (sample group 6) and the Ni plated stainless steel 316 coating (sample group 8).

\subsection{Effect of coating surface roughness on the corrosion behavior}

Previously, it was found that the sample group 3 (ground Hastelloy C-276 coating) and the sample group 7 (ground stainless steel 316 coating) had better corrosion resistances property than the sample group 2 (as sprayed Hastelloy C-276 coating) and the sample group 6 (as sprayed stainless steel 316 coating) because of the reduced depth of the pit due to the new surface being denser.

When the Hastelloy C-276 and the stainless steel 316 coating surfaces were ground down to achieve smoother surfaces, followed by an electroplating of $\mathrm{Ni}$, the result shows an improvement in the corrosion behavior of the sample as evidence in Figs.9 and 10. The $\mathrm{E}_{\text {corr }}$ value of the Ni plated and ground coating is relatively high, reflecting a good resistance to corrosion in $\mathrm{NaOH}$ solution of the coating system. The corrosion rate was also improved as indicated by the shifting of the curve to a lower current density than the Ni plated on as-sprayed coating. The smoothened surface has a better corrosion resistant property than the rough as sprayed surface because of the smooth and near-defect-free surface of the Ni plating layer, allowing less localized attack. With less discontinuity in the coating, a more uniform corrosion can take place resulting in a more continuous protective scale. A denser and more uniform scale can, thus, provide a better corrosion resistance for the coating.

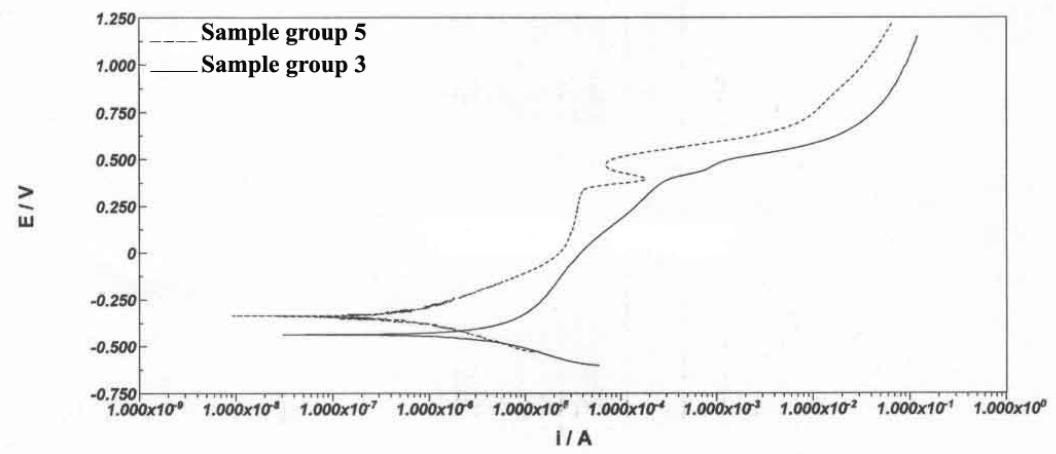

Fig. 9 Polarization curves of the ground Hastelloy C-276 coating (sample group 3) and the Ni plated on ground Hastelloy C-276 coating (sample group 5).

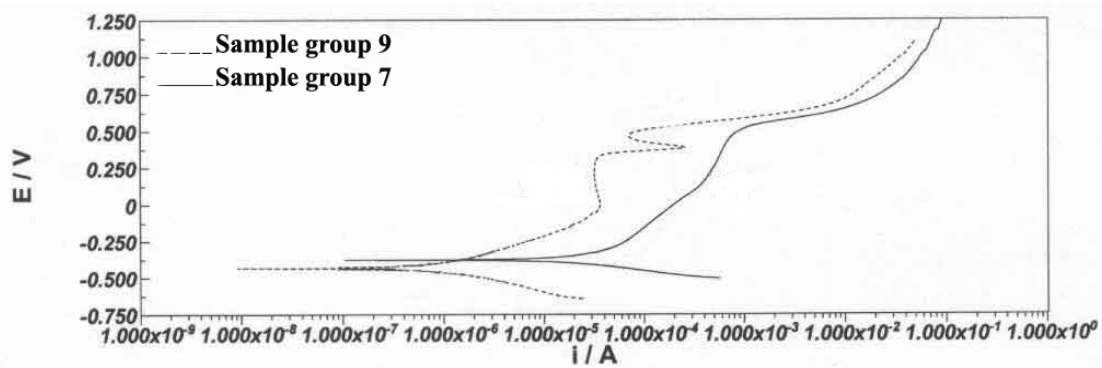

Fig. 10 Polarization curves of the ground stainless steel 316 coating (sample group 7) and the Ni plated on ground stainless steel 316 coating (sample group 9). 
In the as sprayed condition, the Hastelloy C-276 coating exhibits higher corrosion rate than the stainless steel 316 coating, see Fig.11 and Fig.12. The cross-section of the as sprayed Hastelloy C-276 coating in Fig.13 (a) and the cross-section of the as sprayed stainless steel 316 coating in Fig. 13 (b) shows that the as sprayed Hastelloy C-276 coating contains higher un-melt particles and crevice regions, which affect the corrosion rate of the coating.

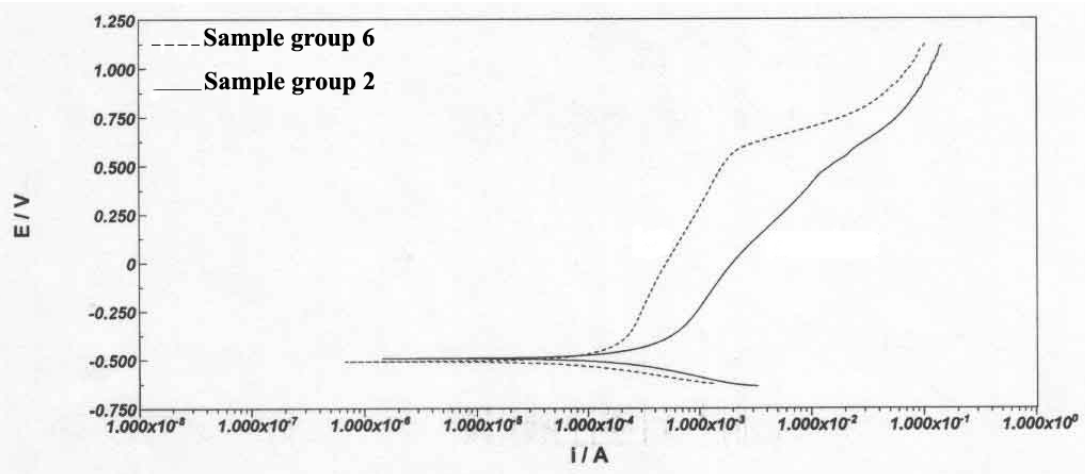

Fig. 11 Polarization curves of the as sprayed Hastelloy C-276 coating (sample group 2) and the as sprayed stainless steel 316 coating (sample group 6).

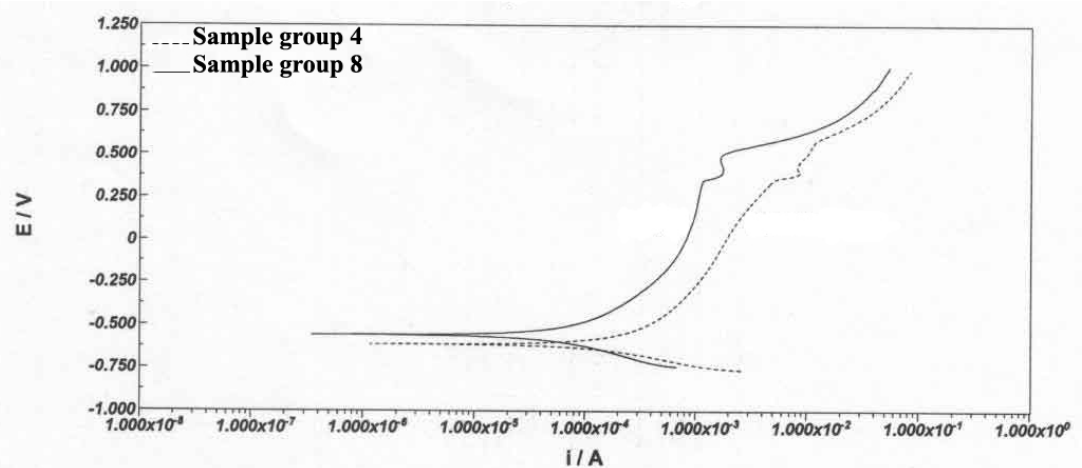

Fig. 12 Polarization curves of the Ni plated Hastelloy C-276 coating (sample group 4) and the Ni plated stainless steel 316 coating (sample group 8).

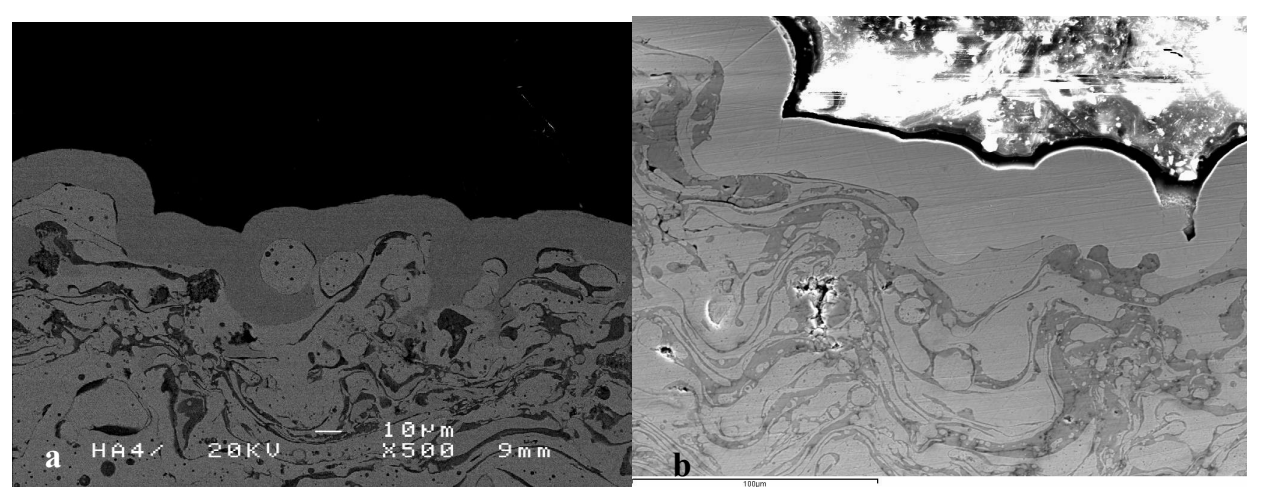

Fig.13 (a) The cross-section of the as sprayed Hastelloy C-276 coating (b) The cross-section of the as sprayed stainless steel 316 coating.

After grinding to smoothen the surfaces to achieve the roughness of about $0.2 \mu \mathrm{m} \mathrm{Ra}$, the corrosion rate of the Hastelloy C-276 coating is now superior to that of the stainless steel 316 coating which is shown in Fig.14 and Fig.15. The better corrosion behavior of the Hastelloy C-276 coating is most likely to be due to its intrinsic property. The previous result on sample 10 and 11 support this assumption. 


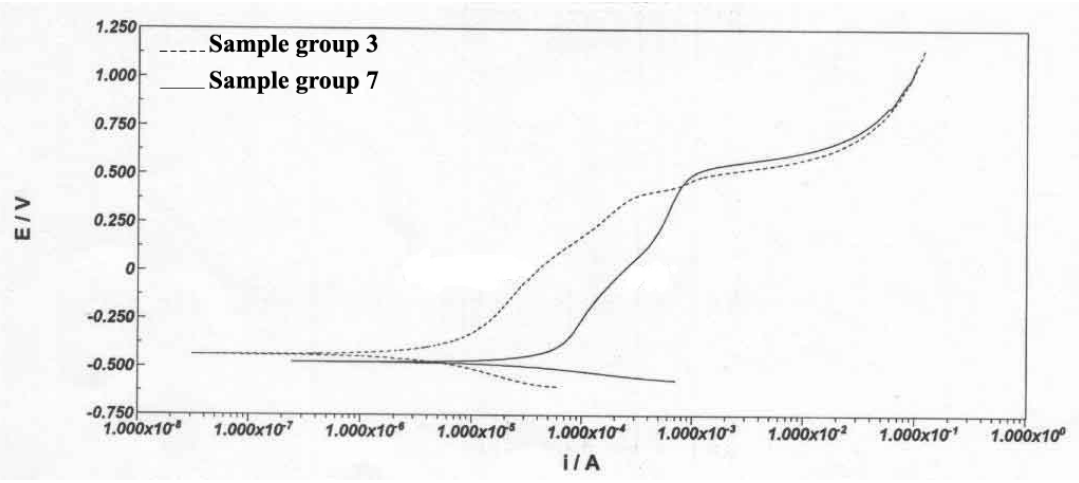

Fig. 14 Polarization curves of the ground Hastelloy C-276 coating (sample group 3) and the ground stainless steel 316 coating (sample group 7).

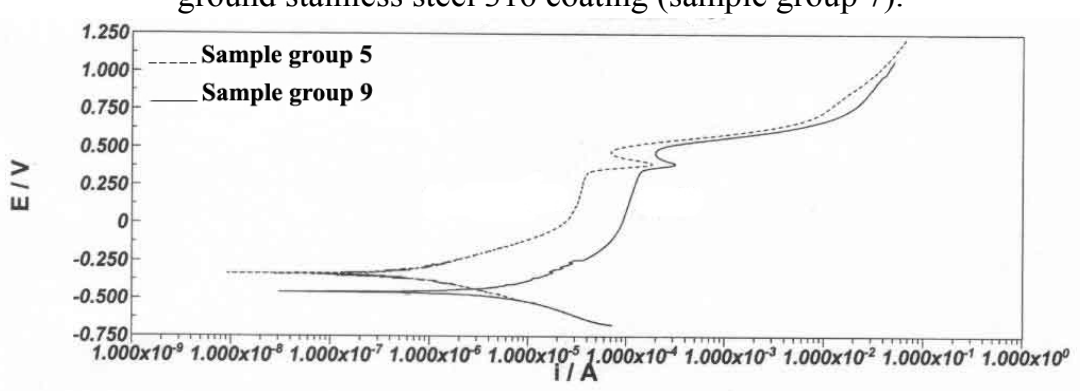

Fig. 15 Polarization curves of the Ni plated on ground Hastelloy C-276 coating (sample group 5) and the Ni plated on ground stainless steel 316 coating (sample group 9).

$$
\mathrm{CR}=\mathrm{KI}_{\text {corr }} \mathrm{EW} / \mathrm{d}
$$

$\mathrm{CR}$ is the corrosion rate ( $\mathrm{mm} /$ year)

$\mathrm{I}_{\text {corr }}$ is the corrosion current density in microamps $/ \mathrm{cm}^{2}$

$\mathrm{K}$ is a constant that defines the units for the corrosion rate $\left(3.27 \times 10^{-3}\right)$

$\mathrm{EW}$ is the equivalent weight in grams

$\mathrm{d}$ is density in grams $/ \mathrm{cm}^{3}$

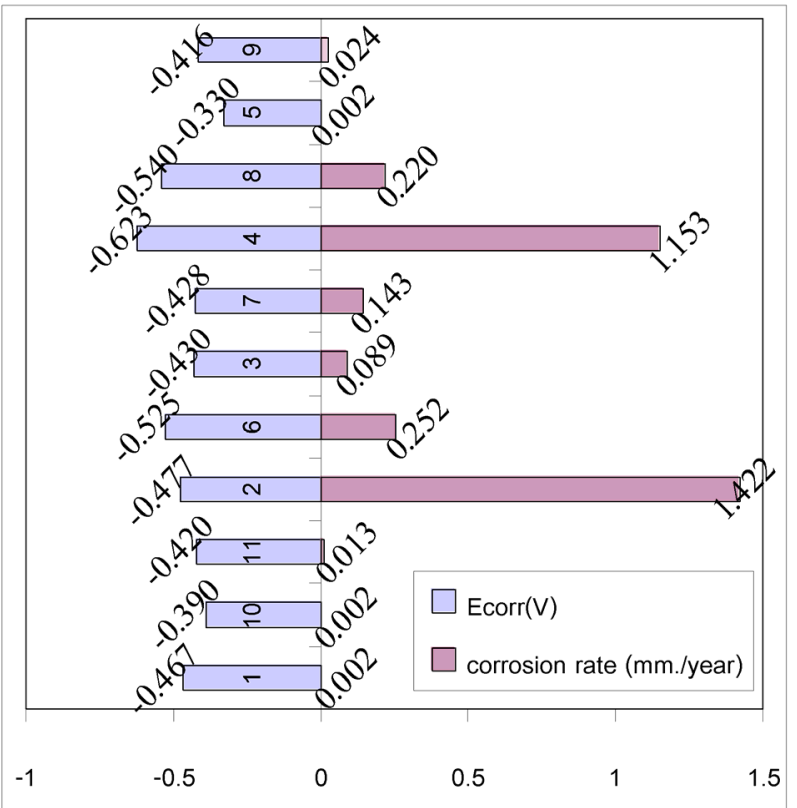

Fig. 16 Corrosion potential (V) and Corrosion rate (mm. per year) of the sample. The numbers designates the sample group. 
Figure 16 presents the average $\mathrm{E}_{\text {corr }}$ values and the corrosion rates of each group of samples. The $\mathrm{E}_{\text {corr }}$ is the electrode potential when corrosion begins, which shows the susceptibility to corrosion of the sample while the corrosion rates were calculated using Tafel extrapolation method and Eq. 1. The $\mathrm{E}_{\text {corr }}$ value of the sample group 1 (the bulk stainless steel 304 substrate) is lower than that of the sample group 10 (the Hastelloy C-276 wire) and the sample group 11 (the stainless steel 316 wire). It indicates that the stainless steel 304 substrate corrodes easier than the Hastelloy C-276 and the stainless steel 316 wires. Nevertheless, the bulk stainless steel 304 substrate exhibits a lower corrosion rate than the Hastelloy C-276 and the stainless steel 316 wires.

The $\mathrm{E}_{\text {corr }}$ values of the as sprayed samples (sample group 2 and 6) are lower than those of the ground samples (sample group 3 and 7). It indicates that the rough EAS coating surface can corrode easier than the smoothened EAS coating surface. Moreover, the corrosion rates of the as sprayed coatings are higher than those of the ground coatings. The Ni plated, non smoothened coatings (sample group 4 and 8 ) and the Ni plated and ground coatings (sample group 5 and 9) also emphasize the effect of coating surface roughness. The $\mathrm{E}_{\text {corr }}$ value of the Ni plated, non smoothened coating is lower than the Ni plated and the ground coating. It means the rough EAS coating surface can corrode easier than the smoothened EAS coating surface. The corrosion rate of the Ni plated and as sprayed coating is higher than that of the Ni plated and ground coating. It shows that the smoothened EAS coating surface possesses higher durability than the rough EAS coating surface.

Comparison between the Ni plated and as sprayed coatings (sample group 4 and 8) and the as sprayed coatings (sample group 2 and 6) show that the $\mathrm{E}_{\text {corr }}$ value and the corrosion rates of the Ni plated samples are lower than those of the un-plated sample, which shows that the Ni plated sample can start corroding easier than the un-plated sample but its corrosion rate is slightly lower than the un-plated ones. The Ni plated and ground coatings (sample group 5 and 9) possess higher $E_{\text {corr }}$ values and corrosion rates than the un-plated and ground coatings (sample group 3 and 7), which indicates that the Ni plating and grinding of coatings can improve the corrosion resistance of the thermal sprayed coating.

The $\mathrm{E}_{\text {corr }}$ value of the as sprayed Hastelloy C-276 coating (sample group 2) is lower than that of the as sprayed stainless steel 316 coating (sample group 6). Moreover the corrosion rate of the as sprayed Hastelloy C-276 coating is higher than that of the as sprayed stainless steel 316 coating. The Ni plated, non smoothened Hastelloy C-276 coating (sample group 4) possesses lower $\mathrm{E}_{\text {corr }}$ value and higher corrosion rate than the Ni plated, non smoothened stainless steel 316 coating (sample group 8). These indicate that the as sprayed stainless steel 316 coating has higher durability than the as sprayed Hastelloy C-276 coating. However the ground stainless steel 316 coatings both plated and un-plated (sample group 7 and 9) possess lower $\mathrm{E}_{\text {corr }}$ value and higher corrosion rate than the ground Hastelloy C-276 coatings both plated and un-plated (sample group 3 and 5). The ground Hastelloy C-276 coating exhibits higher durability than the ground stainless steel 316 coating because the un-melt particles and deep crevices were removed from the coating surface. The Hastelloy C-276 coating can exhibits its intrinsic property. Follow the standard emf series is shown nickel is noble than chromium ${ }^{(9)}$.

\section{Conclusion}

The corrosion resistances of the Hastelloy C-276 and the stainless steel 316 coatings, produced by EAS technique, can be improved using the electroplating of Ni. Grinding of the EAS coatings can effectively provide a better corrosion resistance because the un-melt particles, large pores and the crevices are removed from the coating surface. The ground Hastelloy C-276 coating has higher corrosion resistance than the ground stainless steel 316 coating. The electroplating of $\mathrm{Ni}$ on the ground coatings can seal off the surface pores and provide a smooth finish to the samples, enhancing the corrosion resistance of the coatings. 
Sealing of the EAS coating using electroplating of $\mathrm{Ni}$ should extend the limit of EAS coating in immersion condition.

\section{Acknowledgement}

The authors would like to thank the Metrohm Siam Ltd. and the Failures Analysis and Materials Degradation (FAMD), MTEC, for the use of their equipments. We are also very much grateful to Assistant professor Siriluck Nivitchanyong for many useful discussions.

\section{Reference}

[1] Cramer, S.D. and Covino, B.S. Jr., ed., ASM Handbook Vol.13A: Corrosion: Fundamentals, testing, and protection, ASM International, Ohio, (2003), p. 804.

[2] Unger, R.H., Belashchenko, V.E., Kratochvil, W.R., Dunkerley, J.P., Sedov, V. and Smith, E.A., A new arc spray system to spray high density, low oxide coatings, Proceedings of the $15^{\text {th }}$ International Thermal Spray Conference, Nice, France, May. 25-29, Vol. 2, (1998), pp 1489-1493.

[3] Tucker, R.C. Jr., Surface engineering technologies, Advanced materials\& processes, Vol.160, No. 4, (2002),pp 36-38.

[4] Shreir, L.L., Jarman, R.A. and Burstein, G.T., ed., Corrosion: corrosion control, 2, $3^{\text {rd }}$ Edition, England, Butterworth Heinemann Ltd, (1994), p. 13:78.

[5] Niranatlumpong, P. and Koiprasert, H., Improved corrosion resistance of thermally sprayed coating via surface grinding and electroplating techniques., Surface \& Coatings Technology, Vol. 201, (2006), pp 737-743.

[6] Marijan, D., Slavković, R. and Vuković, M., Surface Modification of Stainless Steel-304 Electrode. 2 .An Experimental Comparative Study of Electrochemically, Hydrothermally and Chemically Modified Oxide Films, Croat. Chem. Acta, Vol. 72, No. 4, (1999), pp 751-761.

[7] Shreir, L.L., Jarman, R.A., and Burstein, G.T., Corrosion Vol.1: Metal/Environment reactions, $3^{\text {rd }}$ Edition, Butterworth Heinemann, (1994), p. 4:125.

[8] Lawrence, J.K., Lawrence, J.K., David, L.O., Joseph, R.D., James, D.D., Heather, J.F., George, M.C., Diane, M.J., Robert, L.S., Kathleen, M.M., Metals Handbook Corrosion, Vol.13, $9^{\text {th }}$ Edition, Ohio, ASM International, (1987), p. 213.

[9] Fontana, M.G., corrosion engineering, $3^{\text {rd }}$ Edition, McGraw-Hill book company, Singapore, (1987), pp 42-43. 